\title{
Research on Application of Clothing Formal Beauty Principle on
}

\section{Knitwear Design}

\author{
Xiaoli Luan ${ }^{1}$ \\ ${ }^{\mathrm{a}}$ email \\ ${ }^{1}$ Jiangxi Institute of Fashion Technology, Nanchang, Jiangxi, China, 330201
}

Keywords: Formal Beauty Principle; Knitwear; Design

\begin{abstract}
In today's knitwear designs, clothing Beauty Principle more and more people pay attention to it in a regular clothing style beauty standards summarized. With the continuous expansion of its influence, it is continuously applied to the popular knitwear designs. Firstly, the concept of clothing formal beauty law summarized, and then based on the basics of the law of formal beauty of clothing, from the melody, proportion, balance, illusion and salient points in these areas are analyzed in-depth inquiry Aesthetic Principles in knitwear design application, and then hope for knitwear design effects play a catalytic role in icing on the cake.
\end{abstract}

\section{Introduction}

In the apparel industry, both in the knitwear market demand scale, or on clothing styles, it can be regarded as a category. Especially in recent years, in the development of knitwear in the category, quantity and quality of rapid transition from the start to the traditional art knitted underwear fashion underwear, underwear, and other fields of health, more innovative style. Meanwhile underwear personalized, fashion and gentrification slowly become distinct characteristics knitwear development. Other knitted clothing, such as knitting casual wear, sportswear and shirts T-shirts and fashionable fabrics in addition to outside, based on their fashion, constantly exposed to consumers. But with this popularity continues to accelerate, consumers knitwear requirements are constantly increasing. In the purchase of clothing, it is more emphasis on the realization of their own temperament and personality, in other words, consumers are increasingly seeking formal beauty of knitted garments.

Based on people's requirements and formal beauty knitwear design quickly upgrade the level of practical needs, it is necessary for specific applications in the knitwear Beauty Principle of exhaustive research.

\section{The Summary of Clothing Formal Beauty Principle}

Clothing Beauty Principle refers to the natural beauty on the basis of the system analysis conducted, summarize, and appropriate use of the natural beauty and a summary. Clothing formal beauty of nature rule change is effective coordination and harmonization of these two opposing element, it adopted a large number of artistic form, such as landscape design. Building architecture, sculpture and painting dance drama. At the same time as one of aesthetic rules, it is today the clothing design criteria during the structural design. Beauty Principle for clothing, for its essence is a kind of clothing construction and design reflected a law of formal beauty. It is based on the natural law of the United States and a corresponding clothing of generalization. The main contents of that law 
melody, proportion, depending on the balance and the outstanding point of this and other aspects. Applied to clothing design time and reflected in the selection of clothing styles and colors of clothing and pondering. Artistic clothing, but more practical, so the law of formal beauty that should be used in clothing design among this way, we are more conducive to the expression of beauty, to better understand the beauty in both form and content internal relations.

\section{The law applied in clothing formal beauty of knitted garments Design}

For knitwear point in the design process, a variety of factors line, surface, and the like, by "Melody" to complete, it can be a sense of rhythm through the appropriate design to achieve a rhythm in the above, mainly through Have these three repeat patterns and gradients ways to reflect. For example, the above fold the laundry, it is through a narrow width of a repetitive design, only to be reflected in a regular rhythm. In addition, for the kind of lotus-like repeat, then highlights a sequential dynamic jump. There are white gradient pattern repeat, it is the best way to reflect a repeat of the melody. At the same time based on arithmetic sequence and geometric sequence relationship of design to achieve color crescendo or decrescendo effective performance. S For the top of the clothes line, with the color of the gradient will appear graded from coarse to fine or fine to coarse graded so that the observer to produce a stretch of psychological sense of rhythm, and then feel carefree.

All artistic creation, will follow the appropriate proportions to express the beauty of the artistic image, and thus meet the aesthetic needs of people. Generally, the smaller the ratio between the difference are more able to achieve a coordinated effect, but will make little difference in the viewer a sense of fatigue visual above. That the difference between those that appear similar, once beyond the aesthetic audience can bear, there will be based on the proportion of the irrationality of the audience caused by boredom or fatigue. This "proportional" in knitwear design is more gradual, golden and random proportions of the three cases. These three golden use most. Under normal circumstances, this golden ratio performance in costume design for the two combination of equipment design, the ratio of the size of the two parts is preferably set to $8: 5$ or $5: 3$, just like the golden ratio, will give a beauty experience. It is also easy to win the favor of consumers visual. But with the progress of time, different definitions of the trend, the proportion of the various aesthetic is changing, not static. In many cases designers will aid the poor ratio of effective fashion show, like mink fluff sweater lengthening accompanied casual miniskirt or a short jacket leather jacket coupled with long pants, are breaking the previous traditional design proportional basis, give people a feeling of beauty and stunning visual.

It is a balance in the clothing Beauty Principle in the content and form of the two major factors clothes carried out effectively combined relationship aims to give people a feeling of calm and serene above. Worn clothing unfolded balance can make people feel comfortable, otherwise it will make people uncomfortable looking at my heart. For example, the above clothing pockets and collar, if properly designed units, balanced and orderly, you can bring simple and secure feeling. Especially for occupational well-fitted design, focusing on people that look elegant, dignified expression. While balancing also allows the presence of asymmetry, such as knitted T-shirts in the pocket, asymmetrical design of the collar, you can give people a feeling of lively and clever, artistic expression highlighting freshness. In addition, for clothing design grasp of color, but also pay attention to the sense of balance, including the proper balance of color hue, purity and other aspects of

Here, the term illusion, usually known as the as the wrong turn, refers to people due to the interference of external things affect the objective or the wrong kind of feeling people under internal psychological impact of it on. In fashion design should be a variety of phenomena to 
control as the wrong order windfall As a designer fashion design during the design beyond the original creative works better outside. On classification, illusions are mainly contrast and segmentations are two types of illusion. For comparison illusion first case, its function is to some shortcomings on the human body effectively improve and make up, like many small chest female, you can tie a knot, folds, or lace and other styles to achieve visual effects to expand the chest. For segmentation illusion, in the design process, not vertical, horizontal and inclined, etc. specific segment, no matter how divided, will make the partition dividing line density, orientation and position of different effects. Typically, the use of the slash dividing most common case, this division brought about by the effect of illusion inseparable slash dividing process in inclination, the inclination to the horizontal or vertical bias when brought illusion with effect on the performance level similar to or similar to the vertical, thus making the current costume design for increasing the use of slash separated.

The so-called salient points refers to a kind of "stressing that" the expression, when that expression would like to highlight one aspect by means of effective primary and secondary sense of the expression to show the right place to be expressed. In knitwear design process, there is a lot of need for the performance of the salient points, such as the chest, back, shoulders, neck and other parts, during the approach above expression, there is a style, make integration for Three practices emphasized. For example, it is for the national style, in Japan and India and other Asian countries, the salient points in knitwear design process lies in the rational use of shawls, embroidered collar and stand. In addition, usually in casual knitwear design process to effectively add motion elements, but also a emphasis on the outstanding point. And thus more able to demonstrate the kind worn such clothes young vibrant vitality. However, this effect of the salient points highlighted in expressing themselves body will be affected, but also greatly affected. Human body because of the differences in height and weight, different body type of knitted garments during selection, the need for clothing design salient points necessary to control, in order to put on such clothing to highlight the body is more perfect, and weakness is not more prominent on the body.

\section{REFERENCE:}

[1] Zhang Xuejiao. Knitwear Design "Law of Formal Beauty" Applications [J]. Liaoning Radio And Television University, 2015,02: 88-89.

[2] Zhang Jiaojian. Valerian And Twist Wool Felt Combined In The Process Of Knitted Garments Design [D]. Beijing Institute of Clothing, 2015.

[3] Wu Yu Fei. Post-Impressionist Paintings Applied Research [D]. In Knitwear Design. Zhejiang University of Technology, 2014.

[4] Guan Tianyu. Innovation Research [D]. Chinese Traditional Culture in Fashion Design of Changchun University of Technology, 2013.

[5] Wu Huan. "Bohemian Style" Applied Research in Children's Clothing Design [D]. Donghua University, 2011.

[6] Liu Ting. Knit Dress Prototype Test and Its Application in Fashion Design [D]. Nanjing Arts Institute, 2009.

[7] Jia Yongfeng. Graffiti Artwork Again in Modern Knitwear Design [J]. Guangxi Textile Science, 2009,06: 44-45. 